\title{
Forget the stress: retrograde amnesia for the stress-induced impairment of extinction retrieval
}

\author{
James F. Briggs and Kaitlyn M. McMullen \\ Department of Psychology, Susquehanna University, Selinsgrove, Pennsylvania 17870, USA
}

\begin{abstract}
We investigated whether cycloheximide (CHX) would induce amnesia for the stress-induced impairment of extinction retrieval. First, a single restraint stress session was demonstrated to impair extinction retrieval, but not fear conditioning. A second experiment showed that when $\mathrm{CHX}$ was administered immediately after restraint, rats exhibited significant extinction retrieval at test (i.e., retrograde amnesia for the stress). In a third experiment, the stress session impaired various amounts of extinction durations, suggesting that the stress inhibited extinction retrieval rather than enhancing the original fear learning. These results suggest memories for acute stress are susceptible to disruption, which could have clinical implications.
\end{abstract}

Exposure therapy, an effective and widely used treatment for anxiety disorders (e.g., specific phobias, obsessive compulsive disorder, and posttraumatic stress disorder) is based on the principles of experimental extinction learning (Mineka and Zinbarg 2006; Telch et al. 2014). Extinction is a procedure where cues (conditioned stimuli-CS) that have been previously paired with a biologically relevant reinforcer (unconditioned stimuli-US) are presented without the reinforcement. This unreinforced cue exposure causes a reduction in the learned response (conditioned response-CR). Using similar procedures, exposure therapies involve presenting the individual with the fear-provoking stimuli with the objective of reducing fear. However, although there is a reduction in the $\mathrm{CR}$, it is now widely accepted that extinction does not involve unlearning of the original association, but rather new learning (Bouton 2002, 2004). Moreover, research has shown that extinction learning forms a separate competing memory that is susceptible to disruption and shares similar characteristics with original acquisition memories (Suzuki et al. 2004; Power et al. 2006; Briggs and Riccio 2007; Briggs and Olson 2013).

Various stressors occurring prior to conditioning and extinction have been shown to disrupt extinction performance, while either enhancing or having little to no effect on original acquisition. For example, chronic restraint stress ( $3 \mathrm{~h}$ a day for a week) impaired extinction recall in rats using a conditioned emotional response task (Miracle et al. 2006). Elevated platform stress has also been shown to disrupt extinction in rats after auditory and contextual fear conditioning (Akirav and Maroun 2007), as well as an inhibitory avoidance task (Ganon-Elazar and Akirav 2009). In addition, forced swim stress in a mouse model has prevented extinction retrieval using a cued fear task (Izquierdo et al. 2006), and the single-prolonged stress (SPS) protocol which includes three stressors of restraint stress, swim test, and exposure to ether has been shown to disrupt extinction using various learning paradigms (for review, see Lisieski et al. 2018). Possible neural mechanisms for the stress-induced blocking of extinction have been linked to alterations in various extinction circuits, including the prefrontal cortex, the hippocampus, and the amygdala (for review, see Maren and Holmes 2016). This stress-induced impairment of extinction is problematic for exposure therapies that are used to treat various anxiety disorders and posttraumatic stress disorder because

\section{Corresponding author: briggsj@susqu.edu}

Article is online at http://www.learnmem.org/cgi/doi/10.1101/lm.051078. 119. any stress or stress response occurring before treatment involving exposure to the fearful stimuli could impact extinction learning.

That various stress protocols disrupt the retrieval of fear extinction while leaving the original acquisition intact suggests that the expression or retrieval of extinction (i.e., reduction of fear) may be inhibited. Thus, we sought to investigate whether there was a memory for the stress event that competed with extinction learning for behavioral control. If so, we hypothesized that amnesia for the stress would allow the retrieval of extinction, which would result in effective reduction of fear. In fact, others have demonstrated blocking the stress-induced impairment of extinction by lesioning the infralimbic cortex (Farrell et al. 2010) and by injecting neuropeptide $S$ into the lateral amygdala (Chauveau et al. 2012). Additionally, it has been reported that the NMDA agonist D-cycloserine, which has been shown to enhance learning, into the BLA can reverse the detrimental effects of stress on extinction retention (Akirav et al. 2009; Yamamoto et al. 2008). Thus, the aim of the current research was to examine whether a memory for a stress event would be susceptible to the traditional amnestic agent cycloheximide (CHX), a protein synthesis inhibitor.

In Experiment 1, we first sought to replicate the stress-induced impairment of extinction retrieval using a passive avoidance procedure in adult female Long-Evans rats. The rats were randomly assigned to one of four groups (see Table 1) before two groups received a single restraint stress session. The stress consisted of restraining the rats in a plastic restraint cone, DecapiCone (Braintree Scientific, Inc.), so that they were immobile for 60 min. Nonstress controls remained undisturbed in their home cages. Forty-eight hours after the stress session, all animals received punishment training.

Training, extinction, and testing were conducted in a blackwhite passive-avoidance chamber that was divided into two compartments (Ugo Basile Model 7551). Training involved placing the rat in the white side of the shuttle box with the door closed, then after a brief period (15 sec), the door was opened allowing the rat to cross to the black side. A control unit timed the latency to cross into the black compartment (in seconds). Once the rat

(C) 2020 Briggs and McMullen This article is distributed exclusively by Cold Spring Harbor Laboratory Press for the first 12 months after the full-issue publication date (see http://learnmem.cshlp.org/site/misc/terms.xhtml). After 12 months, it is available under a Creative Commons License (AttributionNonCommercial 4.0 International), as described at http://creativecommons. org/licenses/by-nc/4.0/. 
Table 1. Experimental design for Experiment 1

\begin{tabular}{|c|c|c|c|c|c|c|c|}
\hline Group & Stress & $48 \mathrm{~h}$ & Training & $24 \mathrm{~h}$ & $\begin{array}{c}\text { Probe/ } \\
\text { Extinction }\end{array}$ & $24 \mathrm{~h}$ & Test \\
\hline No Ext & No & & Yes & & No & & Yes \\
\hline Extinction & No & & Yes & & Yes & & Yes \\
\hline $\begin{array}{c}\text { Stress/No } \\
\text { Ext }\end{array}$ & Yes & & Yes & & No & & Yes \\
\hline Stress/Ext & Yes & & Yes & & Yes & & Yes \\
\hline
\end{tabular}

Ext, extinction; $n=9$ for each group.

entered the black side, the door closed and a single inescapable footshock ( $1 \mathrm{sec}, 0.8 \mathrm{~mA}$ ) was delivered. The footshock was administered $3 \mathrm{sec}$ after the door closed and the animal was removed $12 \mathrm{sec}$ following the footshock. This fear conditioning produces fear of the black compartment. Mean cross latencies for the groups at training ranged from 14.7 to $16.9 \mathrm{sec}$. An ANOVA revealed no differences in cross latencies at training among the four groups $\left(F_{(3,32)}=0.068, P>0.50\right)$.

Twenty-four hours after being trained, two of the four groups (one stressed and one nonstressed) received a single extinction trial. In this session, rats first received a 1-min probe trial to assess initial avoidance before being forced to the black compartment. Each rat was first placed in the white compartment of the shuttle box for $15 \mathrm{sec}$, then the door separating the compartments opened allowing the animals access to the black compartment. The door remained open for $1 \mathrm{~min}$. No animals crossed during the fear probe trial. After $1 \mathrm{~min}$, the animal was removed from the white compartment and was placed in the black compartment for 10 min. Rats were not able to cross between compartments during the extinction session, as the door was closed at all times. The parameters chosen for extinction were similar to those of previous studies (Briggs and Riccio 2007; Briggs and Olson 2013). Two nonextinction control groups (one stressed and one nonstressed) did not receive the probe trial or extinction, but were merely tested to evaluate the level of fear without any extinction treatment.

Twenty-four hours after the extinction session and $48 \mathrm{~h}$ after training for the no extinction control groups, all rats underwent passive-avoidance testing. Test trials were conducted identically to training trials with the rat starting in the white side of the shuttle box, except that no shocks were delivered upon entering the black compartment. After crossing to the black side, the door automatically closed, and the rat was removed from the chamber and returned to its home cage. Testing lasted for $5 \mathrm{~min}$, and the rats that did not cross to the black compartment were removed from the white side. The latency to cross to the black compartment (in seconds) was recorded as the dependent measure.

Figure 1 shows the mean cross latencies for all four groups at test. An ANOVA revealed that the groups differed significantly, $F_{(3,32)}=4.89, P=0.007$. Tukey HSD multiple comparison procedures were used to compare group differences. As can be seen, the No Ext, Stress/No Ext, and Stress/Ext groups all had long cross latencies and there were no differences among those three groups $(P ' s>0.05)$. The Extinction group showed less fear (shorter latencies) and differed significantly from the other three groups $\left(P^{\prime} \mathrm{s}<\right.$ 0.049 ), illustrating that the $10 \mathrm{~min}$ of exposure to the black side was sufficient to produce extinction. Importantly, however, the extinction group that received restraint stress prior to training had significantly longer latencies compared to the extinction only group $(P<0.049)$, demonstrating that the restraint stress disrupted extinction retrieval.

These results show that an acute restraint stress session $48 \mathrm{~h}$ prior to training ( $72 \mathrm{~h}$ before extinction) can disrupt extinction retention, replicating the stress-induced impairment of extinction.
That original learning occurred (i.e., stressed animals were able to learn to fear the black compartment) while the competing extinction learning was disrupted provides evidence that the stress impaired the retrieval of extinction, and not original acquisition.

Experiment 2 served to determine whether the memory for the acute restraint stress was susceptible to disruption. That is, would the administration of a traditional amnestic agent, the protein synthesis inhibitor CHX, immediately following restraint stress produce retrograde amnesia (i.e., forgetting events that occurred prior to the amnestic insult). If so, this should alleviate the stress-induced impairment of extinction. All stress sessions, training, extinction, and testing were identical to Experiment 1 except where noted. Rats were randomly assigned to one of two groups (see Table 2) and both groups received a single restraint session. After the 1-h restraint, before the animals were removed from the cone, a control group (Saline) received an injection of physiological saline ( $1 \mathrm{mg} / \mathrm{kg}$ ip, $0.9 \%)$ and the other (CHX) was injected with cycloheximide ( $1 \mathrm{mg} / \mathrm{kg}$ ip, premixed concentration of $0.1 \%$; Oxoid Ltd.).

Forty-eight hours after restraint, both groups received training. Mean cross latencies at training were $10.3 \mathrm{sec}$ for the Saline group and $14.0 \mathrm{sec}$ for the CHX group. An independent $t$-test revealed no differences in cross latencies at training between the groups, $t_{(16)}=1.05, P>0.30$. Twenty-four hours after training, both groups received a single extinction session. No animals crossed during the 1-min probe trial. Testing for passive avoidance (fear of black compartment) was conducted $24 \mathrm{~h}$ after extinction. The latency to cross to the black compartment (in seconds) was recorded as the dependent measure.

Figure 2 shows the mean cross latency scores for both groups at testing. An independent $t$-test revealed that the groups differed significantly, $t_{(16)}=2.39, P=0.03$. As can be seen, the CHX group had shorter cross latencies, suggesting that the protein synthesis inhibitor administered immediately after restraint stress alleviated the stress-induced impairment of extinction. Thus, CHX produced retrograde amnesia for the restraint stress session. It is worth noting that the Saline group in this experiment had a similar latency score to the Stress/Ext group in Experiment 1 (168 and 207 sec, respectively), suggesting that the stress-induced impairment of extinction was replicated. Moreover, the CHX group in the second experiment displayed similar latency scores $(65 \mathrm{sec})$ to the

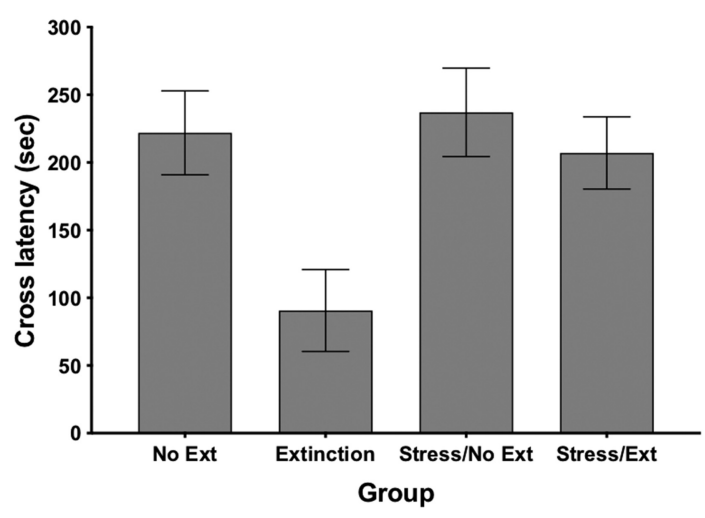

Figure 1. Mean ( \pm SEM) latency to cross to the black side of the blackwhite shuttle box in seconds for all groups in Experiment 1. Long latency scores for the No Ext, Stress/No Ext, and Stress/Ext groups represent significant fear. Decreased latency scores for the group that did not receive stress before training and extinction (Extinction) represents a significant reduction of fear. Increased latency scores for the group that received stress $48 \mathrm{~h}$ before training (Stress/Ext) compared to the no stress extinction group (Extinction) represents the stress induced impairment of extinction. 
Table 2. Experimental design for Experiment 2

\begin{tabular}{lcccccrr}
\hline Group & Stress & Injection & $\mathbf{4 8} \mathbf{h}$ & Training & $\mathbf{2 4} \mathbf{h}$ & Probe/Extinction & $\mathbf{2 4} \mathbf{h}$ \\
\hline Saline & Yes & Saline & Test \\
CHX & Yes & CHX & Yes & Yes & Yes \\
\hline
\end{tabular}

CHX, Cycloheximide; $n=9$ for each group.

Extinction group (91 sec) in Experiment 1, suggesting that the animals that received the amnestic treatment were able to learn and retrieve extinction. To our knowledge, these findings are the first to show that the inhibition of protein synthesis retroactively blocks the effects of stress on extinction. As mentioned above, several studies have demonstrated blocking the stressed-induced impairment of extinction using various agents. The current results suggest that the memory for stress may depend on protein synthesis as do other memories (see Davis and Squire 1984). Understanding the memory mechanisms of stress combined with the impact that stress has on extinction, that is, that the memory for stress may be similar to other memories, could have important clinical implications.

Experiment 3 was conducted to assess whether restraint stress enhanced fear conditioning or blocked the retrieval of extinction. Both enhancing conditioning and blocking extinction could account for the stress-induced impairment of extinction either by making extinction less effective due to stress enhancing fear conditioning or by making extinction less effective due to blocking extinction retrieval, respectively. Stress has been shown to enhance fear learning (Shors et al. 1992; Cordero et al. 2003), which makes it important to determine whether stress enhanced fear conditioning or blocked extinction retrieval in the current paradigm. To test this, we increased the amount of extinction, which has been shown to be effective in decreasing the CR in a variety of learning paradigms (Domjan 2015). Thus, increasing extinction may determine whether stress enhanced conditioning or blocked extinction. We postulated that more extinction would attenuate the stress-induced impairment of extinction observed in our experiments if the effect was due to the enhancement of conditioning; however, if stress impaired the retrieval of extinction, we would continue to observe impaired extinction.

Stress sessions, training, extinction, and testing were identical to Experiment 1 except where noted. Rats were randomly assigned to one of eight groups (see Table 3) before four groups received a single restraint session. The nonstress groups remained in their home cages. Forty-eight hours after stress, all animals received punishment training. Mean cross latencies for the groups at training ranged from 10.8 to $14.8 \mathrm{sec}$. An ANOVA revealed no differences in cross latencies at training among the groups $\left(F_{(7,64)}=\right.$ $0.387, P>0.50)$. Extinction occurred $24 \mathrm{~h}$ after training. For extinction, two groups (a stressed group and a nonstressed group) received either $10 \mathrm{~min}, 15 \mathrm{~min}$, or $20 \mathrm{~min}$ of extinction. Two fear control groups (No Ext) did not receive extinction. No animals crossed during the extinction probe trial. Testing for passive avoidance (fear of black compartment) was conducted $24 \mathrm{~h}$ after extinction. The latency to cross to the black compartment (in seconds) was recorded as the dependent measure.

Figure 3 shows the mean cross latency scores for all groups at testing. An ANOVA revealed that the groups differed significantly, $F_{(7,64)}=9.43, P<0.001$. Tukey HSD multiple comparison procedures were used to compare differences between the groups. As can be seen, the No Ext control fear groups exhibited long cross latencies and were not different $(P>0.05)$. The nonstressed extinction groups all had significantly shorter latencies compared to the no extinction controls $\left(P^{\prime} \mathrm{s}<0.007\right)$, suggesting that the various extinction durations were effective at reducing fear. The stressed extinction groups, however, all exhibited long latency scores and were not different than the stressed No Ext control group ( $\left(P^{\prime} \mathrm{s}>\right.$ $0.05)$ nor different from each other $\left(P^{\prime} \mathrm{s}>0.05\right)$. Thus, increasing the cue exposure duration failed to alleviate the stress-induced impairment of extinction. From these results we postulate that the stress-induced impairment of extinction in this paradigm results from blocking extinction retrieval, rather than enhancing fear conditioning. These findings are consistent with other research demonstrating that various stressors disrupt the retrieval of extinction in human and nonhuman models (Lisieski et al. 2018). If the stress does in fact prevent extinction retrieval then the retrograde amnesia observed in Experiment 2 was due to forgetting of the stress effects inhibiting the retrieval of extinction.

It is important to know whether the beneficial results that lead to the retrieval of extinction produced by amnesia for stress is due to the inhibition of protein synthesis inhibition, that is, the prevention of consolidation (McGaugh 2000), or through other potential mechanisms such as the retrieval-based hypothesis of retrograde amnesia (Gisquet-Verrier et al. 2015). We have begun investigating whether retrograde amnesia for acute restraint stress memories shares similar characteristics with original acquisition memories (e.g., a temporal gradient). In addition, research investigating whether memories for other stress paradigms (e.g., SPS, elevated platform) that impair extinction retrieval are also vulnerable to disruption could lead to further insight into the memory mechanisms of the stressed-induced impairment of extinction. Understanding the mechanisms involved in the stressed-induced impairment of extinction could lead to better exposure-based therapies.

In summary, the current findings contribute to the literature on retrograde amnesia by demonstrating that acute restraint stress is susceptible to disruption induced by a protein synthesis inhibitor. In addition, these results indicate that memories for stress events may be similar to other memories. Moreover, that the retrograde amnesia for stress alleviated the impairment of extinction

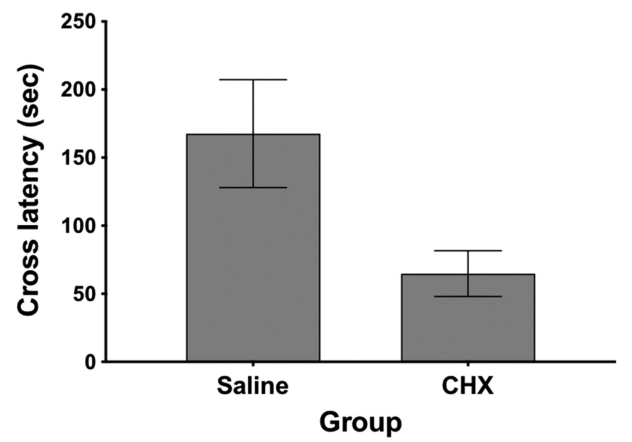

Figure 2. Mean $( \pm S E M)$ latency to cross to the black side of the blackwhite shuttle box in seconds for both groups in Experiment 2. Longer latency scores for the Saline group that was stressed $48 \mathrm{~h}$ prior to training replicates the stressed induced impairment of extinction. Decreased latency scores for the group injected with $\mathrm{CHX}$ following stress compared to the increased scores for the Saline group shows retrograde amnesia for the stress memory. 
Table 3. Experimental design for Experiment 3

\begin{tabular}{|c|c|c|c|c|c|c|c|}
\hline Group & Stress & $48 \mathrm{~h}$ & Training & $24 \mathrm{~h}$ & Probe/Extinction & $24 \mathrm{~h}$ & Test \\
\hline NS-No Ext & No & & Yes & & No & & $\overline{\text { Yes }}$ \\
\hline S-No Ext & Yes & & Yes & & No & & Yes \\
\hline NS-10 min Ext & No & & Yes & & $10 \mathrm{~min}$ & & Yes \\
\hline $\mathrm{S}-10 \mathrm{~min}$ Ext & Yes & & Yes & & $10 \mathrm{~min}$ & & Yes \\
\hline NS $-15 \mathrm{~min}$ Ext & No & & Yes & & $15 \mathrm{~min}$ & & Yes \\
\hline $\mathrm{S}-15 \mathrm{~min}$ Ext & Yes & & Yes & & $15 \mathrm{~min}$ & & Yes \\
\hline $\mathrm{NS}-20 \mathrm{~min}$ Ext & No & & Yes & & $20 \mathrm{~min}$ & & Yes \\
\hline$S-20 \min$ Ext & Yes & & Yes & & $20 \mathrm{~min}$ & & Yes \\
\hline
\end{tabular}

NS, No Stress; S, Stress; $n=9$ for each group.

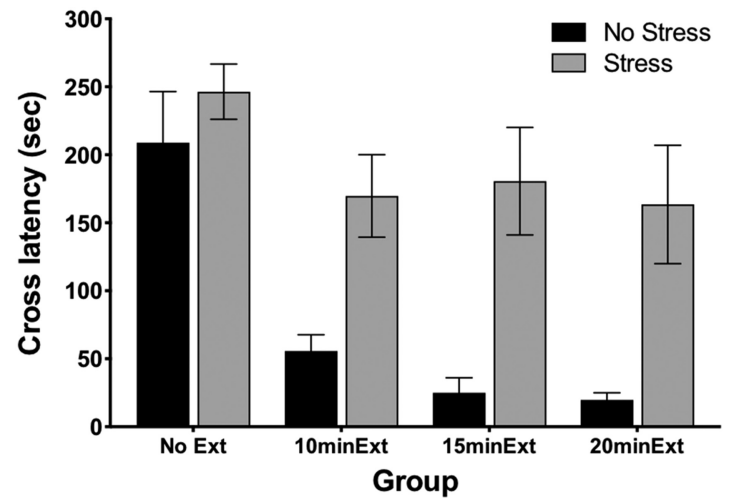

Figure 3. Mean ( \pm SEM) latency to cross to the black side of the blackwhite shuttle box in seconds for all groups in Experiment 3. Dark bars represent the no stress control groups. Light shaded bars represent the stressed experimental groups. Long latency scores for the two No Ext control groups represent significant fear. Shorter latency scores for the No Stress extinction groups represents significant extinction. The longer latencies for the Stress extinction groups demonstrate that stress prior to training and extinction impaired the various amounts of cue exposure duration.

suggests that forgetting the stress could enhance extinction learning, which could have clinical applications.

\section{Acknowledgments}

Partial funding of this research was provided by a Susquehanna University Committee on Faculty Scholarship grant to J.F.B. The authors acknowledge the helpful contributions of Kristina Sanders to this project.

\section{References}

Akirav I, Maroun M. 2007. The role of the medial prefrontal cortex-amygdala circuit in stress effects on the extinction of fear. Neural Plast 2007: 30873. doi: $10.1155 / 2007 / 30873$

Akirav I, Segev A, Motanis H, Maroun M. 2009. D-cycloserine into the BLA reverses the impairing effects of exposure to stress on the extinction of contextual fear, but not conditioned taste aversion. Learn Mem 16: 682686. doi:10.1101/lm.1565109

Bouton ME. 2002. Context, ambiguity, and unlearning: sources of relapse after behavioral extinction. Biol Psychiatry 52: 976-986. doi:10.1016/ S0006-3223(02)01546-9

Bouton ME. 2004. Context and behavioral processes in extinction. Learn Mem 11: 485-494. doi:10.1101/1m.78804

Briggs JF, Olson BP. 2013. Reexposure to the amnestic agent alleviates cycloheximide-induced retrograde amnesia for reactivated and extinction memories. Learn Mem 20: 285-288. doi:10.1101/lm.030270 .113

Briggs JF, Riccio DC. 2007. Retrograde amnesia for extinction: similarities with amnesia for original acquisition memories. Learn Behav 35: 131140. doi:10.3758/BF03193048
Chauveau F, Lange MD, Jüngling K, Lesting J, Siedenbecher T, Pape H-C. 2012. Prevention of stress-impaired fear extinction through neuropeptide $S$ action in the lateral amygdala. Neuropsychopharmacology 37: 1588-1599. doi:10.1038/npp.2012.3

Cordero MI, Venero C, Kruyt ND, Sandi C. 2003. Prior exposure to a single stress facilitates subsequent contextual fear conditioning in rats: evidence for a role of corticosterone. Horm Behav 44: 338-345. doi:10 .1016/S0018-506X(03)00160-0

Davis HP, Squire LR. 1984. Protein synthesis and memory: a review. Psychol Bull 96: 518-559. doi:10.1037/0033-2909.96.3.518

Domjan M. 2015. The principles of learning and behavior, 7 th ed. Cengage Learning, Stamford, CT.

Farrell MR, Sayed JA, Underwood AR, Wellman CL. 2010. Lesion of infralimbic cortex occludes stress effects on retrieval of extinction but not fear conditioning. Neurobiol Learn Mem 94: 240-246. doi:10.1016/j .nlm.2010.06.001

Ganon-Elazar E, Akirav I. 2009. Cannabinoid receptor activation in the basolateral amygdala blocks the effects of stress on the conditioning and extinction of inhibitory avoidance. J Neurosci 29: 11078-11088. doi:10 .1523/JNEUROSCI.1223-09.2009

Gisquet-Verrier P, Lynch JF III, Cutolo P, Toledano D, Ulmen A, Jasnow AM, Riccio DC. 2015. Integration of new information with active memory accounts for retrograde amnesia: a challenge to the consolidation/ reconsolidation hypothesis? J Neurosci 35: 11623-11633. doi:10.1523/ JNEUROSCI.1386-15.2015

Izquierdo A, Wellman CL, Holmes A. 2006. Brief uncontrollable stress causes dendritic retraction in infralimbic cortex and resistance to fear extinction in mice. J Neurosci 26: 5733-5738. doi:10.1523/JNEUROSCI .0474-06.2006

Lisieski MJ, Eagle AL, Conti AC, Liberzon I, Perrine SA. 2018. Single-prolonged stress: a review of two decades of progress in a rodent model of post-traumatic stress disorder. Front Psychiatry 9: 196. doi:10 $.3389 /$ fpsyt.2018.00196

Maren S, Holmes A. 2016. Stress and fear extinction. Neuropsychopharmacology 41: 58-79. doi:10.1038/npp.2015.180

McGaugh JL. 2000. Memory - a century of consolidation. Science 287: 248251. doi:10.1126/science.287.5451.248

Mineka S, Zinbarg R. 2006. A contemporary learning theory perspective on the etiology of anxiety disorders. Am Psychol 61: 10-26. doi:10.1037/ 0003-066X.61.1.10

Miracle AD, Brace MF, Huyck KD, Singler SA, Wellman CL. 2006. Chronic stress impairs recall of extinction of conditioned fear. Neurobiol Learn Mem 85: 213-218. doi:10.1016/j.nlm.2005.10.005

Power AE, Berlau DJ, McGaugh JL, Steward O. 2006. Anisomycin infused into the hippocampus fails to block "reconsolidation" but impairs extinction: the role of re-exposure duration. Learn Mem 13: 27-34. doi:10.1101/lm.91206

Shors TJ, Weiss C, Thompson RF. 1992. Stress-induced facilitation of classical conditioning. Science 257: 537-539. doi:10.1126/science .1636089

Suzuki A, Josselyn SA, Frankland PW, Masushige S, Silva AJ, Kida S. 2004. Memory reconsolidation and extinction have distinct temporal and biochemical signatures. J Neurosci 24: 4787-4795. doi:10.1523/ JNEUROSCI.5491-03.2004

Telch MJ, Cobb AR, Lancaster CL. 2014. Exposure therapy. In The Wiley handbook of anxiety disorders (ed. Emmelkamp P, Ehring T), pp. 717-756. John Wiley \& Sons, New York.

Yamamoto S, Morinobu S, Fuchikami M, Kurata A, Kozuru T, Yamawki S. 2008. Effects of single prolonged stress and D-Cycloserine on contextual fear extinction and hippocampal NMDA receptor expression in a rat model of PTSD. Neuropsychopharmacology 33: 2108-2116. doi:10.1038/ sj.npp. 1301605

Received October 20, 2019; accepted in revised form January 17, 2020. 


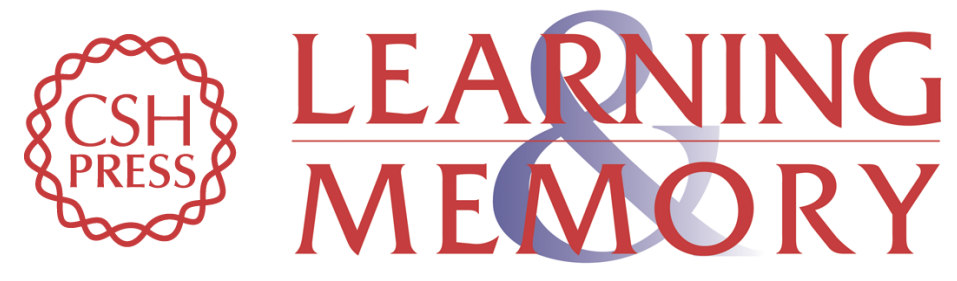

\section{Forget the stress: retrograde amnesia for the stress-induced impairment of extinction retrieval}

James F. Briggs and Kaitlyn M. McMullen

Learn. Mem. 2020, 27:

Access the most recent version at doi:10.1101/lm.051078.119

References This article cites 22 articles, 10 of which can be accessed free at: http://learnmem.cshlp.org/content/27/5/173.full.html\#ref-list-1

Creative This article is distributed exclusively by Cold Spring Harbor Laboratory Press for the Commons License first 12 months after the full-issue publication date (see

http://learnmem.cshlp.org/site/misc/terms.xhtml). After 12 months, it is available under a Creative Commons License (Attribution-NonCommercial 4.0 International), as described at http://creativecommons.org/licenses/by-nc/4.0/.

Email Alerting Receive free email alerts when new articles cite this article - sign up in the box at the Service top right corner of the article or click here. 